BMJ Open

Diabetes

Research

\& Care

\title{
Gestational diabetes mellitus treatment reduces obesity-induced adverse pregnancy and neonatal outcomes: the St. Carlos gestational study
}

To cite: Assaf-Balut C, Familiar C, García de la Torre N, et al. Gestational diabetes mellitus treatment reduces obesity-induced adverse pregnancy and neonatal outcomes: the St. Carlos gestational study. BMJ Open Diabetes Research and Care 2016:4:e000314. doi:10.1136/bmjdrc-2016000314

Received 21 August 2016 Revised 23 September 2016 Accepted 19 October 2016

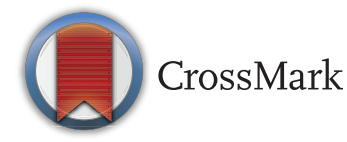

${ }^{1}$ Endocrinology and Nutrition Department, Hospital Clínico San Carlos, Madrid, Spain ${ }^{2}$ Facultad de Medicina, Universidad Complutense de Madrid, Madrid, Spain ${ }^{3}$ Gynecology and Obstetrics Department, Madrid, Spain ${ }^{4}$ Clinical Laboratory Department, Madrid, Spain Hospital Clínico San CarlosIdISSC, Madrid, Spain

Correspondence to Dr Alfonso L Calle-Pascual; acallepascual@hotmail.com

\author{
Carla Assaf-Balut, ${ }^{1}$ Cristina Familiar, ${ }^{1}$ Nuria García de la Torre, ${ }^{1}$ Miguel A Rubio, ${ }^{1,2}$ \\ Elena Bordiú, ${ }^{1,2}$ Laura del Valle, ${ }^{1}$ Miriam Lara, ${ }^{1}$ Teresa Ruiz, ${ }^{1}$ Ana Ortolá, ${ }^{1}$ \\ Irene Crespo, ${ }^{1}$ Alejandra Duran, ${ }^{1,2}$ Miguel A Herraiz, ${ }^{2,3}$ Nuria Izquierdo, ${ }^{2,3}$ \\ Noelia Perez, ${ }^{2,3}$ Maria J Torrejon, ${ }^{1,4}$ Isabelle Runkle, ${ }^{1,2}$ Carmen Montañez, ${ }^{1}$ \\ Alfonso L Calle-Pascual ${ }^{1,2}$
}

\section{ABSTRACT}

Background: Obesity and gestational diabetes mellitus (GDM) increase the morbidity of the mother and newborn, which could increase further should they coexist. We aimed to determine the risk of adverse pregnancy and neonatal outcomes associated with excess weight (EW), and within this group identify potential differences between those with and without GDM.

Methods: We carried out a post-hoc analysis of the St. Carlos Gestational Study which included 3312 pregnant women, arranged in 3 groups: normal-weight women (NWw) (2398/72.4\%), overweight women (OWw) (649/19.6\%) and obese women (OBw) (265/ $8 \%$ ). OWW and OBW were grouped as EW women $(E W w)$. We analyzed variables related to adverse pregnancy and neonatal outcomes.

Results: The relative risk $(95 \% \mathrm{Cl})$ for GDM was 1.82 (1.47 to $2.25 ; p<0.0001$ ) for $0 \mathrm{Ww}$, and 3.26 (2.45 to 4.35; $p<0.0001)$ in $0 \mathrm{Bw}$. Univariate analysis showed associations of EW to higher rates of prematurity, birth weight $>90$ th centile, newborns admitted to neonatal intensive care unit (NICU), instrumental delivery and cesarean delivery (all $p<0.005$ ). Multivariate analysis, adjusted for parity and ethnicity, showed that EW increased the risk of prematurity, admission to NICU, cesarean and instrumental delivery, especially in EWw without GDM. NWw with GDM had a significantly lower risk of admission to NICU and cesarean delivery, compared with NWw without GDM.

Conclusions: EW is detrimental for pregnancy and neonatal outcomes, and treatment of GDM contributes to lowering the risk in EWw and NWw. Applying the same lifestyle changes to all pregnant women, independent of their weight or GDM condition, could improve these outcomes.

\section{INTRODUCTION}

Adverse maternal and neonatal outcomes are determined by two main risk factors: excess weight (EW) and hyperglycemia. ${ }^{1-3}$ Both are intimately related $^{4-6}$ where having excess

\section{Significance of this study}

What is already known about this subject?

- Adverse maternal and neonatal outcomes are determined by two main risk factors: excess weight and hyperglycemia.

What are the new findings?

- Our study reveals that any state of excess weight is associated with an increased risk of adverse events. However, we failed to establish these same associations with gestational diabetes mellitus (GDM) since our data shows that women with excess weight and GDM did not have an added risk for complications and that it could even, in some cases, have a protective role.

How might these results change the focus of research or clinical practice?

- Such intervention aims to change lifestyle patterns of pregnant women to reduce adverse outcomes of GDM, which seems to benefit both normal-weight women and excess-weight women.

body mass index (BMI) increases the risk of having gestational diabetes mellitus (GDM). Previous studies have shown strong associations between pregestational obesity (OB) and increased maternal and neonatal morbidity, ${ }^{7-13}$ and similar results were found in those who gained excessive body weight during pregnancy. ${ }^{14-16}$ On the other hand, GDM significantly increases the risk for obstetric complications. ${ }^{2}{ }^{3}$ Considering that both EW and GDM coexist frequently because of their shared physiopathological characteristics derived from insulin resistance, it becomes rather challenging to determine the specific effects on maternal and neonatal outcomes of each one independently. 
Recently the Hyperglycemia and Adverse Pregnancy Outcome (HAPO) study $^{7}{ }^{8}$ revealed OB as being an independent risk factor for adverse maternal and neonatal outcomes, where GDM was found to provide an added risk. In this study those women diagnosed with GDM were not treated and only those who met the diagnostic criteria for diabetes were.

Changes in lifestyle, including nutritional habits and physical activity, are a key measure adopted in the handling of hyperglycemia in pregnant women. These measures have shown improvements in obstetric and neonatal complications. While a few studies have suggested betterments in women treated before the pregnancy, ${ }^{17}$ others where treatment measures were adopted during the pregnancy showed mixed results. ${ }^{18-20}$ These results ranged from lacking improvements in pregnancy outcomes to having some in certain analyzed variables.

The St. Carlos Gestational Study ${ }^{21}$ has recently shown a 3.5-fold increase of GDM after the adoption of the International Association of Diabetes and Pregnancy Study Groups criteria (IADPSGc). However, parallel to this increase, a decrease in adverse maternal and neonatal outcomes was observed following the treatment of these women. Hence, this presents an opportunity to analyze $\mathrm{EW}$ as an independent risk factor for adverse maternal and neonatal outcomes through evaluation of the potential differences between women with pregestational EW and normal weight (NW). Additionally, we tried to determine whether women with EW and diagnosed with GDM (subjected to a specific intervention and follow-up) had lower risk for maternal and neonatal complications compared with those with EW who did not have GDM (who only received standard maternity care). We hypothesize that the negative impact of EW in pregnancy and neonatal complications can be significantly lowered when GDM is diagnosed and treated. Consequently, we carried out a post-hoc analysis of the St. Carlos Gestational Study.

\section{SUBJECTS AND METHODS \\ Study design}

The St. Carlos Hospital (HCSC) covers a population of 440000 and it is the only specialized center in the heart of the Community of Madrid where centralized and universal screening of GDM is carried out. Our hospital is equipped with a specialized endocrinology unit (diabetes and pregnancy unit) where the management and follow-up of patients with GDM takes place. In April 2012 our endocrinology department adopted the application of the IADPSGc for the GDM diagnosis, switching from the former use of the CarpenterCoustan criteria (CCc). This all lead to the emergence of the St. Carlos' study which in turn motivated this post-hoc analysis.

\section{Study population}

A total of 3312 pregnant women receiving prenatal medical care at the HCSC, who were screened for GDM at 24-28 weeks of gestation using an oral glucose tolerance test (OGTT) from April 2011 to March 2013, were included in this study. The population had a mean age of 31.6 years and the mean maternal BMI at the OGTT was $25.8 \mathrm{~kg} / \mathrm{m}^{2}$. Mean prepregnancy BMI (PPBMI), calculated based on patients' self-reported prepregnancy body weight (PPBW), was $23 \mathrm{~kg} / \mathrm{m}^{2}$. Pregnant women were categorized into three groups according to PPBMI: normal-weight women $(\mathrm{NWw})<25 \mathrm{~kg} / \mathrm{m}^{2}, \quad(2398 /$ $72.4 \%$ ), overweight women (OWw) $25-29.9 \mathrm{~kg} / \mathrm{m}^{2}$, $(649 / 19.6 \%)$ and obese women $(\mathrm{OBw}) \geq 30 \mathrm{~kg} / \mathrm{m}^{2}$, $(265 / 8 \%)$. For GDM diagnosis, CCc were applied from April 2011 to March 2012 and IADPSGc from April 2012 to March 2013.

\section{Clinical variables}

Demographic and clinical baseline variables regarding maternal characteristics were collected at the time of the OGTT, reflected in table 1 . These variables were based on aspects regarding age at pregnancy diagnosis (years), ethnicity (Caucasian, Hispanic, African, Asian, and others), self-reported maternal PPBW $(\mathrm{kg})$, PPBMI $\left(\mathrm{kg} / \mathrm{m}^{2}\right)$, weight gain until the week of the OGTT, smoking habit, parity, family history of any component of metabolic syndrome (MetS) and history of prior miscarriage or GDM. Since women were followed up until delivery, we also collected data regarding adverse pregnancy and neonatal outcomes related to: gestation (gestational hypertension), delivery (cesarean and instrumental deliveries) and neonate status ( prematurity $<37$ weeks, birth weight $<10$ th centile and $>90$ th centile, admission to neonatal intensive care unit (NICU), Apgar score $<7$ at $1 \mathrm{~min}$ ).

\section{GDM—lifestyle treatment procedure}

Women diagnosed with GDM were referred to the Diabetes and Pregnancy Unit of the HCSC where they were given lifestyle and dietary recommendations ${ }^{21}$ aimed at an optimal glucose control. These recommendations were built on Mediterranean diet principles, based on a daily consumption of at least two servings of vegetables, at least two pieces of fruit, increasing intake of extra virgin olive oil, oily fish, nuts, whole grain cereals and skimmed milk while avoiding processed foods, cakes, pastries, soft drinks and juices. They were simultaneously encouraged to increase their aerobic physical activity, daily when possible. The glycemic targets were defined by fasting and preprandial glucose $<90 \mathrm{mg} / \mathrm{dL}(5 \mathrm{mmol} / \mathrm{L})$ and 1-hour postmeal $<120 \mathrm{mg} / \mathrm{dL} \quad(6.6 \mathrm{mmol} / \mathrm{L})$. These measures were not aimed at a weight loss, which however could have happened indirectly. Patients without GDM received a standard pregnancy follow-up at the obstetric clinic. For all pregnant women weight gain during pregnancy depended on their PPBMI, where NWw, OWw and OBw were recommended to gain a total of $11.5-16 \mathrm{~kg}(0.42 \mathrm{~kg} /$ per week), $7-11.5 \mathrm{~kg}$ (0.28 kg/per week) and $5-9 \mathrm{~kg}(0.22 \mathrm{~kg} /$ per week), respectively. 
Table 1 Characteristics of maternal population, gestation and delivery outcomes by prepregnancy BMI $\left(\mathrm{kg} / \mathrm{m}^{2}\right)$

\begin{tabular}{|c|c|c|c|c|c|c|c|}
\hline & All & $<25 \mathrm{~kg} / \mathrm{m}^{2}$ & $25-29.9 \mathrm{~kg} / \mathrm{m}^{2}$ & $\begin{array}{l}\text { p Value } 25-29.9 \text { vs } \\
<25 \mathrm{~kg} / \mathrm{m}^{2}\end{array}$ & $\geq 30 \mathrm{~kg} / \mathrm{m}^{2}$ & $\begin{array}{l}\text { p Value } \geq 30 \text { vs } \\
<25 \mathrm{~kg} / \mathrm{m}^{2}\end{array}$ & $\begin{array}{l}\text { p Value } \geq 25 \text { vs } \\
<25 \mathrm{~kg} / \mathrm{m}^{2}\end{array}$ \\
\hline $\mathrm{N}$ & 3312 & 2398 (72.4) & $649(19.6)$ & & $265(8.0)$ & & \\
\hline Age (year) & $31.6 \pm 5.7$ & $31.5 \pm 5.8$ & $32.2 \pm 5.6$ & 0.093 & $31.7 \pm 5.5$ & 0.865 & 0.372 \\
\hline BW (kg) & $69.4 \pm 12.5$ & $63.3+6.4$ & $75.2 \pm 7.3$ & 0.0001 & $87.8 \pm 12.8$ & 0.001 & 0.0001 \\
\hline BMI $\left(\mathrm{kg} / \mathrm{m}^{2}\right)$ & $25.8 \pm 3.1$ & $23.9 \pm 2.4$ & $29.0 \pm 1.9$ & 0.0001 & $33.9 \pm 2.9$ & 0.001 & 0.0001 \\
\hline WG at screening & $25.2 \pm 3.1$ & $25.1+2.8$ & $25.4 \pm 4.2$ & 0.959 & $25.3 \pm 3.1$ & 0.325 & 0.834 \\
\hline Prepregnancy BW (kg) & $61.9 \pm 11.7$ & $56.9 \pm 6.6$ & $69.9 \pm 6.9$ & 0.0001 & $84.7 \pm 5.7$ & 0.001 & 0.0001 \\
\hline Prepregnancy BMI $\left(\mathrm{kg} / \mathrm{m}^{2}\right)$ & $23.0 \pm 4.3$ & $21.5 \pm 2.1$ & $27.0 \pm 1.4$ & 0.0001 & $32.7 \pm 2.2$ & 0.001 & 0.0001 \\
\hline Weight gain at screening & $6.0 \pm 4.4$ & $6.5 \pm 4.3$ & $5.2 \pm 3.9$ & 0.001 & $3.6 \pm 5.4$ & 0.001 & 0.001 \\
\hline$\leq 5 \mathrm{~kg}$ & $1468(34.0)$ & $667(27.8)$ & $303(46.7)$ & 0.001 & $155(58.6)$ & 0.001 & 0.001 \\
\hline$>5 \mathrm{~kg}$ & $2187(66.0)$ & $1731(72.2)$ & 346 (53.3) & 0.001 & $110(41.4)$ & 0.001 & 0.0001 \\
\hline Ethnicity (in rows) & & & & 0.001 & & 0.01 & 0.001 \\
\hline Caucasian & $2056(62.1)$ & 1568 (76.3) & 335 (16.3) & & $153(7.4)$ & & \\
\hline Hispanic & $1140(34.4)$ & $750(65.8)$ & $286(25.1)$ & & $104(9.1)$ & & \\
\hline African & $39(1.2)$ & $35(89.7)$ & $2(5.1)$ & & $2(5.1)$ & & \\
\hline Asian & $59(1.8)$ & $31(52.5)$ & $23(39)$ & & $5(8.5)$ & & \\
\hline Others & $18(0.1)$ & $13(72.2)$ & $3(16.7)$ & & $2(11.1)$ & & \\
\hline Parity: primiparous & 1469 (44.4) & 1158 (48.3) & 218 (33.6) & 0.001 & $93(35.2)$ & 0.001 & 0.001 \\
\hline Prenatal smoker & $438(13.5)$ & $336(14.0)$ & $74(11.4)$ & 0.088 & $28(10.8)$ & 0.252 & 0.282 \\
\hline Current smoker & $356(10.8)$ & $254(10.6)$ & 74 (11.4) & 0.075 & $28(10.8)$ & 0.693 & 0.145 \\
\hline Family history of MetS & $1510(45.6)$ & $937(39.1)$ & $385(59.3)$ & 0.001 & $188(70.9)$ & 0.001 & 0.004 \\
\hline Prior miscarriage & $790(23.9)$ & $543(22.6)$ & $180(27.7)$ & 0.001 & $67(25.2)$ & 0.01 & 0.010 \\
\hline Prior GDM & $62(1.9)$ & $39(1.6)$ & $10(1.5)$ & 0.78 & $13(4.9)$ & 0.001 & 0.013 \\
\hline CCc GDM-screens (n) & 1750 & 1185 & 421 & & 144 & & \\
\hline GDM/NGT (n) & $185 / 1565$ & $68 / 1117$ & $82 / 339$ & 0.003 & $35 / 109$ & 0.0001 & 0.0001 \\
\hline GDM rate (\%) & 10.6 & 5.7 & 19.5 & 0.001 & 24.3 & 0.0001 & 0.0001 \\
\hline \multirow[t]{2}{*}{ Weight gain at screening (kg, GDM/NGT) } & $5.9 \pm 6.8 /$ & $7.3 \pm 8.0 /$ & $5.0 \pm 4.2 /$ & 0.005 & $3.1 \pm 4.2 /$ & 0.001 & 0.001 \\
\hline & $6.0 \pm 4.7$ & $6.5 \pm 4.6$ & $4.9 \pm 4.4$ & 0.006 & $3.3 \pm 4.8$ & 0.001 & 0.001 \\
\hline IADPSGc GDM-screens (n) & 1562 & 1213 & 228 & & 121 & & \\
\hline GDM/NGT (n) & $542 / 1020$ & $319 / 894$ & $142 / 86$ & 0.0001 & $81 / 40$ & 0.0001 & 0.0001 \\
\hline GDM rate (\%) & 34.7 & 26.3 & 62.2 & 0.0001 & 66.9 & 0.0001 & 0.0001 \\
\hline \multirow[t]{2}{*}{ Weight gain at screening (kg, GDM/NGT) } & $5.8 \pm 3.8 /$ & $6.5 \pm 3.1 /$ & $5.2 \pm 3.8 /$ & 0.003 & $3.7 \pm 5.3 /$ & 0.0001 & 0.0001 \\
\hline & $6.2 \pm 4.1$ & $6.5 \pm 4.0$ & $5.6 \pm 3.5$ & 0.001 & $4.4 \pm 7.2$ & 0.0001 & 0.001 \\
\hline GDM pooled RR (95\% Cl) & & 1 & $1.82(1.47-2.25)$ & 0.0001 & $3.26(2.45-4.35)$ & 0.001 & \\
\hline \multicolumn{8}{|l|}{ Maternal } \\
\hline Gestational hypertension & $125(3.8)$ & $86(3.6)$ & $28(4.3)$ & 0.502 & $11(5.2)$ & 0.316 & 0.087 \\
\hline Cesarean section & 755 (22.8) & $476(19.8)$ & $189(29.1)$ & 0.01 & $90(34.0)$ & 0.003 & 0.001 \\
\hline Instrumental delivery & $402(12.1)$ & $250(10.4)$ & $95(14.7)$ & 0.013 & 57 (21.6) & 0.01 & 0.014 \\
\hline
\end{tabular}

Results expressed as mean \pm SDM or $\mathrm{n}(\%)$.

BMI, body mass index; BW, body weight; CCc, Carpenter-Coustan criteria; GDM, gestational diabetes mellitus; IADPSGc, International Association of Diabetes and Pregnancy Study Groups criteria; MetS, metabolic syndrome; NGT, normal glucose tolerance; RR, relative risk; WG, weeks of gestation. 


\section{Statistical analysis}

SPSS V.15.0 (SPSS, Chicago, Illinois, USA) was used for statistical analysis. Continuous variables are expressed as mean \pm standard deviation of mean $(\mathrm{SDM})$, and categorical variables as percentages or numbers. The statistical differences between the averages of continuous variables were determined with the Student's t-test or nonparametric Mann-Whitney test and categorical variables by the one-way variance tests and $\chi^{2}$ test. PPBMI categories for univariate analysis were $\mathrm{NWw}$, OWw and OBw. Multivariate analysis adjusted for ethnicity and parity was performed to assess the risk of overweight (OW) and OB with adverse pregnancy and neonatal outcomes, but due to sample size problems both were included in the same group defined as EW women $(\mathrm{EWw})$. Results for each adverse outcome are presented as ORs with 95\% CI. Also, this study's cohort was stratified as follows into five groups considering BMI and the absence or presence of GDM: (a) NWw, no GDM as reference group (b) NWw, GDM, (c) raw EW, (c1) EWw, no GDM, (c2) EWw, GDM. We proceeded to make comparisons of ORs of each group to the group of reference, and determined associations of different maternal PPBMI categories with different adverse pregnancy and neonatal outcomes. Values of $\mathrm{p}<0.05$ were considered significant.

The study protocol was reviewed and approved by the Ethics Committee of the HCSC and conducted according to the Declaration of Helsinki.

\section{RESULTS}

Table 1 shows the characteristics of the studied cohort. $\mathrm{NWw}, \mathrm{OWw}$ and $\mathrm{OBw}$ rates in Caucasians were $76.3 \%$, $16.3 \%$ and $7.4 \%$, respectively, whereas the prevalence of EWw seemed to be more frequent in Hispanics (65.8\%, 25.1 and $9.1 \%$, respectively) as well as in Asians (52.5\%, $39 \%$ and $8 \%$, respectively). OWw and $\mathrm{OBw}$ compared with $\mathrm{NWw}$ had a higher rate of prior miscarriages (27.7\% and $25.5 \%$ vs $22.6 \%$; $\mathrm{p}<0.001$, respectively), had more frequently a family history of MetS $(59.3 \%$ and $70.9 \%$ vs $39.1 \%$; $\mathrm{p}<0.001$, respectively) and were less frequently primiparous $(33.6 \%$ and $35.2 \%$ vs $48.3 \%$; $\mathrm{p}<0.001$, respectively). No differences related to age, smoking and gestational age at diagnosis were observed. Women with EW (OW and $\mathrm{OB}$ ) happened to have gained less weight at GDM screening than those with NW $(5.2+3.9 \mathrm{~kg}$ and $3.6+5.4 \mathrm{~kg}$ vs $6.5 \pm 4.3 \mathrm{~kg} ; \mathrm{p}<0.001$ respectively). Table 1 displays weight gain of women with GDM or normal glucose tolerance (NGT) in both CCc and IADPSGc groups. GDM prevalence in the CCc group was of a $10.6 \%(185 / 1750)$ and in the IADPSGc group was of $34.7 \%(185 / 1750)$. In addition, OWw and OBw had higher GDM rates than NWw, in both the CCc $(82 / 421 \quad(19.5 \%)$ and $35 / 144(24.3 \%)$ vs $68 / 1185$ $(5.7 \%) ; \mathrm{p}<0.0001$, respectively) and IADPSGc group $(142 / 228(62.2 \%)$ and $81 / 121(66.9 \%)$ vs $319 / 1213$ $(26.3 \%) ; \mathrm{p}<0.0001$, respectively). The pooled relative risk $(95 \%$ CI $)$ for GDM was 1.82 (1.47 to 2.25; $\mathrm{p}<0.0001)$ for $\mathrm{OWw}$, and 3.26 (2.45 to 4.35 ; $\mathrm{p}<0.0001$ ) in OBw. Compared with NWw, those with EW had higher rates of Cesarean section (C-section) $(\mathrm{p}<0.001)$ and instrumental delivery $(\mathrm{p}<0.014)$.

Table 2 provides information regarding characteristics of fetal development and newborn. EWw compared with NWw had babies with a higher abdominal circumference $(\mathrm{AC}, \mathrm{cm})$ in the third trimester $(28.5 \pm 2.0$ vs 27.9 \pm 2.5 ; $\mathrm{p}<0.025)$, higher weight estimation $(\mathrm{g}) \quad(2019 \pm 295$ vs $1956 \pm 263 ; \mathrm{p}<0.0001)$ and a lower normal intrauterine growth (NIG) for gestational age in the second trimester which prevailed in the third trimester $(85.3 \%$ vs $87 \%$; $\mathrm{p}<0.019)$. Compared with $\mathrm{NWw}$, those with $\mathrm{EW}$ had higher rates of prematurity $(\mathrm{p}<0.0001)$, newborns with a birth weight $>90$ th centile $(p<0.042)$ and newborns admitted to NICU $(\mathrm{p}<0.001)$.

Table 3 shows a multivariate analysis adjusted for ethnicity and parity clustering both $\mathrm{OWw}$ and $\mathrm{OBw}$ in the same group $(\mathrm{EWw})$, using $\mathrm{NWw}$ with no GDM as the reference group. OR for $\mathrm{EWw}$ were significantly higher for prematurity (OR 2.42 (95\% CI 1.73 to 3.39$)$; $\mathrm{p}<0.0001$ ), admission to NICU (OR 2.93; 95\% CI 2.15 to 3.99; $\mathrm{p}<0.0001$ ), cesarean delivery (OR $1.53 ; 95 \%$ CI 1.19 to $1.97 ; \mathrm{p}<0.001)$ and instrumental delivery (OR 1.35; $95 \%$ CI 1.04 to $1.76 ; \mathrm{p}<0.026)$. This tendency was mainly observed in EWw with no GDM, while ORs for EWw with GDM are similar to those found in the reference group. Moreover, NWw with GDM had a significantly lower risk of admission to NICU (OR 0.61; 95\% CI 0.39 to $0.95 ; \mathrm{p}<0.03$ ) and $\mathrm{C}$-section (OR $0.42 ; 95 \%$ CI 0.31 to $0.57 ; \mathrm{p}<0.001)$, in comparison to NWw without GDM. No significant differences were found in other analyzed variables.

\section{DISCUSSION}

Data obtained in this study associates EWw with having an increased risk of adverse maternal and neonatal outcomes, in particular in terms of rates of GDM, prematurity, birth weight $>90$ th centile, admission to NICU, cesarean and instrumental delivery. After adjusting for confounding factors, EW continued to be associated with higher rates of prematurity, admission to NICU, C-section and instrumental delivery. Surprisingly, the results of this study suggest that these adverse outcomes seem to be somewhat reduced in EWw with GDM, when this condition was treated. In fact, this group displayed similar risks to $\mathrm{NWw}$ with no GDM, leading us to believe that through treatment of GDM adverse pregnancy and neonatal outcomes could be reduced. In addition, NWw with treated GDM had significantly lower rates of admission to NICU and cesarean delivery in comparison to those who did not have GDM. To the best of our knowledge, in all the literature available this is the first study to associate GDM diagnosis with a reduction of adverse pregnancy and neonatal outcomes. However, recently it has been reported how treatment of GDM with nutritional therapy could be associated with having a lower 
Table 2 Characteristics of fetal development (ultrasound data) and newborn by maternal prepregnancy BMI $\left(\mathrm{kg} / \mathrm{m}^{2}\right)$

\begin{tabular}{|c|c|c|c|c|c|c|c|}
\hline & All & $<25 \mathrm{~kg} / \mathrm{m}^{2}$ & $25-29.9 \mathrm{~kg} / \mathrm{m}^{2}$ & $\begin{array}{l}\mathrm{p} \text { Value } 25-29.9 \text { vs } \\
<25 \mathrm{~kg} / \mathrm{m}^{2}\end{array}$ & $\geq 30 \mathrm{~kg} / \mathrm{m}^{2}$ & $\begin{array}{l}\text { p Value } \geq 30 \text { vs } \\
<25 \mathrm{~kg} / \mathrm{m}^{2}\end{array}$ & $\begin{array}{l}\text { p Value } \geq 25 \text { vs } \\
<25 \mathrm{~kg} / \mathrm{m}^{2}\end{array}$ \\
\hline$N$ & 3312 & $2398(72.4)$ & $649(19.6)$ & & $265(8.0)$ & & \\
\hline \multicolumn{8}{|l|}{ Fetal growth } \\
\hline GA at 2nd trimester & $20.3 \pm 3.8$ & $20.2 \pm 1.5$ & $20.5 \pm 8.1$ & 0.179 & $20.4 \pm 1.2$ & 0.151 & 0.165 \\
\hline Biparietal diameter (cm) & $4.9 \pm 1.0$ & $4.9 \pm 1.2$ & $4.8 \pm 0.9$ & 0.185 & $4.9 \pm 0.6$ & 0.866 & 0.234 \\
\hline $\mathrm{AC}(\mathrm{cm})$ & $15.6 \pm 1.5$ & $15.5 \pm 1.8$ & $15.7 \pm 1.8$ & 0.678 & $15.6 \pm 1.5$ & 0.222 & 0.362 \\
\hline Femur length (cm) & $3.3 \pm 0.7$ & $3.3 \pm 0.4$ & $3.3 \pm 0.4$ & 0.377 & $3.5 \pm 1.9$ & 0.001 & 0.029 \\
\hline NIG for GA n (\%) & $2882(87)$ & 2096(87.4) & $554(85.5)$ & 0.016 & $230(86.8)$ & 0.067 & 0.048 \\
\hline GA at 3rd trimester & $32.1 \pm 5.7$ & $32.2 \pm 6.7$ & $32.0 \pm 1.0$ & 0.549 & $32.0 \pm 1.2$ & 0.197 & 0.468 \\
\hline Biparietal diameter (cm) & $8.2 \pm 2.1$ & $8.3 \pm 2.4$ & $8.2 \pm 1.0$ & 0.800 & $8.2 \pm 0.4$ & 0.788 & 0.723 \\
\hline $\mathrm{AC}(\mathrm{cm})$ & $28.1 \pm 2.6$ & $27.9 \pm 2.5$ & $28.6 \pm 2.5$ & 0.034 & $28.5 \pm 2.0$ & 0.001 & 0.025 \\
\hline Femur length $(\mathrm{cm})$ & $6.2 \pm 1.5$ & $6.2 \pm 1.8$ & $6.1 \pm 0.3$ & 0.809 & $6.1 \pm 0.4$ & 0.980 & 0.791 \\
\hline Weight estimation (g) & $1968 \pm 269$ & $1956 \pm 263$ & $1991 \pm 277$ & 0.011 & $2019 \pm 295$ & 0.002 & 0.0001 \\
\hline NIG for GA n (\%) & $2931(86.5)$ & $2086(87)$ & $558(86)$ & 0.049 & $226(85.3)$ & 0.035 & 0.019 \\
\hline \multicolumn{8}{|l|}{ Newborn } \\
\hline GA (weeks) & $39.2 \pm 1.8$ & $39.1 \pm 1.9$ & $38.2 \pm 1.9$ & 0.501 & $38.5 \pm 1.1$ & 0.964 & 0.339 \\
\hline Prematurity (<37 weeks) & $199(6.0)$ & $94(3.9)$ & $64(9.8)$ & 0.001 & $41(15.5)$ & 0.0001 & 0.0001 \\
\hline Birth weight (g) & $3201 \pm 501$ & $3170 \pm 486$ & $3242 \pm 513$ & 0.288 & $3307 \pm 521$ & 0.090 & 0.083 \\
\hline Birth weight $>90$ centile & $148(4.2)$ & $93(3.8)$ & $31(4.8)$ & 0.064 & $24(9.1)$ & 0.001 & 0.042 \\
\hline Birth weight $<10$ centile & $228(6.9)$ & $170(7.1)$ & $38(5.9)$ & 0.091 & $20(7.5)$ & 0.337 & 0.411 \\
\hline Apgar score $<7$ at $1 \mathrm{~min}$ & $120(3.6)$ & $75(3.1)$ & $17(2.7)$ & 0.387 & $28(10.6)$ & 0.190 & 0.202 \\
\hline Admission to NICU & $238(7.2)$ & $110(4.6)$ & $80(12.3)$ & 0.001 & $48(18.1)$ & 0.001 & 0.001 \\
\hline
\end{tabular}

Results expressed as mean \pm SDM or $n(\%)$.

AC, abdominal circumference; BMI, body mass index; GA, gestational age; NICU, neonatal intensive care unit; NIG, normal intrauterine growth. 
Table 3 Relationship between prepregnancy excess weight $\left(\mathrm{BMl} \geq 25 \mathrm{~kg} / \mathrm{m}^{2}\right)$, GDM and outcomes adjusted to parity and ethnicity

\begin{tabular}{|c|c|c|c|}
\hline Outcome & OR & $95 \% \mathrm{Cl}$ & p Value \\
\hline \multicolumn{4}{|l|}{ Prematurity $<37$ weeks } \\
\hline No excess weight no GDM & 1 & & \\
\hline GDM & 0.742 & 0.437 to 1.258 & 0.267 \\
\hline Excess weight & 2.423 & 1.734 to 3.385 & 0.0001 \\
\hline No GDM & 3.144 & 2.148 to 4.593 & 0.0001 \\
\hline GDM & 1.161 & 0.539 to 2.369 & 0.639 \\
\hline \multicolumn{4}{|l|}{ Birth weight $<10$ centile } \\
\hline No excess weight no GDM & 1 & & \\
\hline GDM & 0.893 & 0.592 to 1.346 & 0.588 \\
\hline Excess weight & 1.116 & 0.816 to 1.536 & 0.453 \\
\hline No GDM & 1.145 & 0.785 to 1.677 & 0.450 \\
\hline GDM & 1.023 & 0.562 to 1.835 & 0.967 \\
\hline \multicolumn{4}{|l|}{ Birth weight $>90$ centile } \\
\hline No excess weight no GDM & 1 & & \\
\hline GDM & 0.979 & 0.569 to 1.682 & 0.937 \\
\hline Excess weight & 1.082 & 0.722 to 1.622 & 0.701 \\
\hline No GDM & 1.116 & 0.711 to 1.689 & 0.952 \\
\hline GDM & 1.362 & 0.663 to 2.798 & 0.401 \\
\hline \multicolumn{4}{|l|}{ Apgar score $<7$ at $1 \mathrm{~min}$} \\
\hline No excess weight no GDM & 1 & & \\
\hline GDM & 0.827 & $0.452-1.514$ & 0.539 \\
\hline Excess weight & 1.270 & 0.755 to 2.136 & 0.220 \\
\hline No GDM & 1.273 & 0.672 to 2.413 & 0.284 \\
\hline GDM & 1.363 & 0.544 to 3.423 & 0.511 \\
\hline \multicolumn{4}{|l|}{ Admission to NICU } \\
\hline No excess weight no GDM & 1 & & \\
\hline GDM & 0.610 & 0.390 to 0.953 & 0.030 \\
\hline Excess weight & 2.929 & 2.154 to 3.983 & 0.0001 \\
\hline No GDM & 4.051 & 2.735 to 6.106 & 0.0001 \\
\hline GDM & 1.650 & 1.013 to 2.716 & 0.049 \\
\hline \multicolumn{4}{|l|}{ Gestational hypertension } \\
\hline No excess weight no GDM & 1 & & \\
\hline GDM & 0.658 & 0.394 to 1.100 & 0.110 \\
\hline Excess weight & 1.059 & 0.686 to 1.637 & 0.795 \\
\hline No GDM & 0.738 & 0.347 to 1.531 & 0.403 \\
\hline GDM & 1.229 & 0.717 to 2.107 & 0.454 \\
\hline \multicolumn{4}{|l|}{ Cesarean section } \\
\hline No excess weight no GDM & 1 & & \\
\hline GDM & 0.419 & 0.310 to 0.566 & 0.001 \\
\hline Excess weight & 1.528 & 1.187 to 1.967 & 0.001 \\
\hline No GDM & 1.932 & 1.393 to 2.679 & 0.0001 \\
\hline GDM & 1.050 & 0.701 to 1.575 & 0.724 \\
\hline \multicolumn{4}{|l|}{ Instrumental delivery } \\
\hline No excess weight no GDM & 1 & & \\
\hline GDM & 1.218 & 0.906 to 1.636 & 0.191 \\
\hline Excess weight & 1.349 & 1.036 to 1.755 & 0.026 \\
\hline No GDM & 1.540 & 1.077 to 2.201 & 0.010 \\
\hline GDM & 1.071 & 0.714 to 1.626 & 0.404 \\
\hline
\end{tabular}

BMI, body mass index; GDM, gestational diabetes mellitus; NICU, neonatal intensive care unit.

risk of having certain adverse pregnancy and neonatal outcomes. $^{22}$

The rates of OWw $(19 \%)$ and $\mathrm{OBw}(8 \%)$ are markedly lower to that obtained in the HAPO study ${ }^{7}$ however similar to those provided by other studies performed in the same geographical area as ours ${ }^{623}$ which reports the prevalence of EW in women at childbearing age. ${ }^{24}$ In contrast with the HAPO study, where women meeting GDM criteria were not treated, those in our study were the main focus of treatment is on achieving an optimal glycemic control mainly managed by changing these women's lifestyle, which indirectly positively affected 
weight gain. The main cornerstones of this intervention was both consuming low caloric density and glycemic index foods, ${ }^{21}$ achieved through incorporation of a daily intake of nuts and whole cereals as well as avoidance of foods with a high glycemic index. Women who followed these recommendations had better outcomes than EWw with no GDM. Whether these benefits come from the controlled weight gain that consequently this intervention entails remains unclear because, unfortunately, we were unable include and therefore analyze weight gain after GDM screening in the no GDM group.

As would be expected we found that pregestational EW was associated with higher rates of Hispanic ethnicity, family history of MetS (including OB), obstetric history of prior miscarriages, GDM, and multiparity. ${ }^{6}$ After adjustment, pregestational EW remains associated with higher risks of prematurity, admission to NICU, C-section and instrumental delivery. These findings are in the line with what has been published previously, where OB increases the risk of prematurity, ${ }^{11}{ }^{11}$ cesarean delivery ${ }^{12}$ and admission to NICU. ${ }^{25}$ Pregestational EWw had a significantly higher 2.4-fold risk of prematurity, in particular regarding EWw with no GDM (3.1-fold risk). OB is linked to a proinflammatory status caused by both production of adipokines and cytokines. These make spontaneous labor more probable as they promote cervical ripening and contractions, following stimulation of prostaglandins. ${ }^{10}$ EWw also had a higher risk of instrumental and cesarean deliveries possibly caused by excess adipose tissue in the pelvis which hinders the birth canals. ${ }^{26}$ It could also be owing to slow cervical dilation in $\mathrm{EWw}^{27}$ leading to a longer labor and ultimately resulting in further complications for the mother and the newborn. ${ }^{25-27}$ In fact, babies of EWW have an increased risk of admission to NICU, which could be due to prematurity and loss of fetal wellbeing. Meanwhile, prematurity, C-section, instrumental delivery and admission to NICU rates were lower in EWw with GDM than those without GDM. These results suggest a possible association between diagnosed GDM and better maternal and neonatal outcomes. All these benefits could be because women diagnosed with GDM received specific management (aimed at a control of weight gain and glycemia levels) designed for them. Meanwhile those who did not have GDM received standard follow-up alone.

This study is not without limitations. First, the fact that it is a cross-sectional study and lacks of interventional nature prevents us from being able to establish causality in our results. Moreover, our study population included women diagnosed with GDM based on two different diagnostic criteria, where during the first period the CCc were used and in the second it was the IADPSGc. Another important limitation to consider is the differences in $\mathrm{OB}$ rates between this study and others like the HAPO study ${ }^{3} 8$ where rates of OB were much higher than ours. Our sample size was not big enough, forcing us to unify $\mathrm{OWw}$ and $\mathrm{OBw}$ in one same group of $\mathrm{EWw}$ and possibly entailing differences between the results.
This could have led to differences between our results and those of other studies. Furthermore, pregestational weight is self-reported by patients leading to a possible loss of accuracy of this collected data. Finally, registering weight gain of pregnant women only until GDM screening is an important limitation. Despite this, our study shows associations between $\mathrm{EW}$ and higher rates of adverse outcomes. More importantly, it shows how proper treatment of GDM provides a protective effect against these outcomes.

The findings of this study indicate associations between EW and adverse maternal and neonatal outcomes, where GDM treatment seems to be protective. The loss of weight prior to the pregnancy in EWw should be as important a recommendation as supplementation with folic acid and iodine. While designing the appropriate lifestyle for $\mathrm{EWw}$, the attention should focus on the content itself (a healthy diet, performance of regular physical activity...) but it is also detrimental to facilitate the adherence to this change. A main goal should be to consider counseling as a key aspect, where these women should be educated about GDM risks, as well as discussing individual impediments they might encounter to fulfill the lifestyle changes. ${ }^{28}$ In addition, providing all pregnant women with the same interventional tools used for GDM treatment, regardless of their GDM condition or PPBMI, should be envisioned as a possible universal clinical practice.

Contributors CA-B, TR, CF and ALC-P wrote the manuscript and research data. ALC-P, MAR, MAH, NI, NP and AD contributed to the study concept and design, acquisition of data, analysis and interpretation of data. EB, AO, IC, LdV, IR, NGdIT, CM and MJT take responsibility for universal screening, researched data and drafting of the manuscript. All authors were involved in the critical revision of the manuscript for important intellectual content, material support and study supervision. All authors have seen and agree with the content of the previous version of the manuscript.

Funding This research was supported by grants from Fundación para Estudios Endocrinometabolicos, and IdISSC Hospital Clinico San Carlos, Madrid, and the Instituto de Salud Carlos III of Spain (PI14/01563) and Fondo Europeo de Desarrollo Regional (FEDER). LdV was supported by a grant from the IdISSC and the Fundación para Estudios Endocrinometabólicos. CA-B was supported by a grant from the Fundación para Estudios Endocrinometabólicos.

Disclaimer The design and conduct of the study; collection, management, analysis, and interpretation of the data; preparation, review, and approval of the manuscript; and decision to submit the manuscript for publication are the responsibilities of the authors alone and independent of the funders.

Competing interests None declared.

Patient consent Obtained.

Ethics approval The study protocol was reviewed and approved by the Ethics Committee of the St. Carlos Hospital.

Provenance and peer review Not commissioned; externally peer reviewed.

Data sharing statement No additional data are available.

Open Access This is an Open Access article distributed in accordance with the Creative Commons Attribution Non Commercial (CC BY-NC 4.0) license, which permits others to distribute, remix, adapt, build upon this work noncommercially, and license their derivative works on different terms, provided the original work is properly cited and the use is non-commercial. See: http:// creativecommons.org/licenses/by-nc/4.0/ 


\section{REFERENCES}

1. Owens LA, O'Sullivan EP, Kirwan B, et al. ATLANTIC DIP Collaborators. ATLANTIC DIP. The impact of obesity on pregnancy outcome in glucose-tolerant women. Diabetes Care 2010;33:577-9.

2. Landon MB, Mele L, Spong CY, et al. Eunice Kennedy Shriver National Institute of Child Health, and Human Development (NICHD) Maternal-Fetal Medicine Units (MFMU) Network. The relationship between maternal glycemia and perinatal outcome. Obstet Gynecol 2011;117:218-24.

3. Metzger BE, Lowe LP, Dyer AR, et al. HAPO Study Cooperative Research Group. Hyperglycemia and Adverse Pregnancy Outcomes. N Engl J Med 2008;358:1991-2002.

4. Simmons D. Diabetes and obesity in pregnancy. Best Pract Res Clin Obstet Gynaecol 2011;25:25-36.

5. Bloomgarden ZT. Gestational diabetes mellitus and obesity. Diabetes Care 2010;33:e60-5.

6. Pérez-Ferré N, Fernandez MD, Torrejon MJ, et al. Effect of lifestyle on the risk of gestational diabetes and obstetric outcomes in immigrant Hispanic women living in Spain. J Diabetes 2012;4:432-8.

7. Catalano PM, Mclntyre HD, Cruickshank JK, et al. HAPO Study Cooperative Research Group. The Hyperglycemia and Adverse Pregnancy Outcome study: associations of GDM and obesity with pregnancy outcomes. Diabetes Care 2012;35:780-6.

8. HAPO Study Cooperative Research Group. Hyperglycaemia and Adverse Pregnancy Outcome (HAPO) study: associations with maternal body mass index. BJOG 2010;117:575-84.

9. Valsamakis G, Kyriazi EL, Mouslech Z, et al. Effect of maternal obesity on pregnancy outcomes and long-term metabolic consequences. Hormones (Athens) 2015;14:345-57.

10. Cnattingius $\mathrm{S}$, Villamor $\mathrm{E}$, Johansson $\mathrm{S}$, et al. Maternal obesity and risk of preterm delivery. JAMA 2013;309:2362-70.

11. Minsart AF, Buekens $P$, De Spiegelaere $M$, et al. Neonatal outcomes in obese mothers: a population-based analysis. BMC Pregnancy Childbirth 2013;13:36.

12. Conner SN, Tuuli MG, Longman RE, et al. Impact of obesity on incision-to-delivery interval and neonatal outcomes at cesarean delivery. Am J Obstet Gynecol 2013;209:386.e1-6.

13. Sarkar RK, Cooley SM, Donnelly JC, et al. The incidence and impact of increased body mass index on maternal and fetal morbidity in the low-risk primigravid population. J Matern Fetal Neonatal Med 2007;20:879-83.

14. Flick AA, Brookfield KF, de la Torre L, et al. Excessive weight gain among obese women and pregnancy outcomes. Am J Perinatol 2010;27:333-8.

15. Baci Y, Üstüner I, Keskin HL, et al. Effect of maternal obesity and weight gain on gestational diabetes mellitus. Gynecol Endocrinol 2013;29:133-6.
16. Aviram A, Hod M, Yogev Y. Maternal obesity: implications for pregnancy outcome and long-term risks-a link to maternal nutrition. Int J Gynecol Obstet 2011;115(Suppl 1):S6-10.

17. Agha M, Agha RA, Sandell J. Interventions to reduce and prevent obesity in preconceptual and pregnant women: a systematic review and meta-analysis. PLOS ONE 2014;9:e95132.

18. Poston L, Bell R, Croker $\mathrm{H}$, et al. Effect of a behavioural intervention in obese pregnant women (the UPBEAT study): a multicentre, randomised controlled trial. Lancet Diabetes Endocrinol 2015;3:767-77

19. Koivusalo SB, Rönö K, Klemetti MM, et al. Gestational diabetes mellitus can be prevented by lifestyle intervention: the Finnish Gestational Diabetes Prevention Study (RADIEL): a randomized controlled trial. Diabetes Care 2016;39:24-30.

20. Simmons D, Jelsma JGM, Galjaard S, et al. Results from a European multicenter randomized trial of physical activity and/or healthy eating to reduce the risk of gestational diabetes mellitus: the DALI Lifestyle pilot. Diabetes Care 2015;38:1650-6.

21. Duran A, Sáenz S, Torrejón MJ, et al. Introduction of IADPSG criteria for the screening and diagnosis of gestational diabetes mellitus results in improved pregnancy outcomes at a lower cost in a large cohort of pregnant women: the St. Carlos Gestational Diabetes Study. Diabetes Care 2014;37:2442-50.

22. Kgosidialwa O, Egan AM, Carmody L, et al. Treatment with diet and exercise for women with gestational diabetes mellitus diagnosed using IADPSG criteria. J Clin Endocrinol Metab 2015;100:4629-36.

23. Barquiel B, Herranz L, Riveiro J, et al. The relative contribution of ethnicity, overweight and gestational diabetes severity to postpartum abnormal glucose tolerance. Int J Diabetes Clin Res 2014;1:3.

24. Marcuello C, Calle-Pascual AL, Fuentes M, et al. Prevalence of the metabolic syndrome in Spain using regional cutoff points for waist circumference: the di@ bet.es study. Acta Diabetol 2013;50:615-23.

25. Scott-Pillai R, Spence D, Cardwell CR, et al. The impact of body mass index on maternal and neonatal outcomes: a retrospective study in a UK obstetric population, 2004-2011. BJOG 2013;120:932-9.

26. Vahratian A, Zhang J, Troendle JF, et al. Maternal prepregnancy overweight and obesity and the pattern of labor progression in term nulliparous women. Obstet Gynecol 2004;104:943-51.

27. McDonald SD, Han Z, Mulla S, et al. Overweight and obesity in mothers and risk of preterm birth and low birth weight infants: systematic review and meta-analyses. BMJ 2010;341:c3428.

28. Jelsma JG, van Leeuwen KM, Oostdam N, et al. Beliefs, barriers, and preferences of European overweight women to adopt a healthier lifestyle in pregnancy to minimize risk of developing gestational diabetes mellitus: an explorative study. J Pregnancy 2016;2016:3435791. 